\title{
PII S0049-3848(96)00006-0
}

\section{HYPERCOAGULABILITY AND HYPERFIBRINOLYSIS IN PATIENTS WITH MELAKOMA}

${ }^{+}$B. Bottasso, ${ }^{+}$D. Mari, ${ }^{+}{ }^{+}$R. Coppola, ${ }^{*}{ }^{*} \mathrm{~N}$. Mannucci

${ }^{+}$Angelo Bianchi Bonomi Hemophilia and Thrombosis Center and Institute of Internal Medicine, IRCCS Maggiore Hospital and University of Milan; National Cancer Institute, Surgical oncology Division B, Milan, Italy

(Received 27 September 1995 by Editor G.F. Gensini; revised/accepted 8 December 1995)

\begin{abstract}
The purpose of this study was to evaluate whether or not, using sensitive analytical methods for the measurement of coagulation and fibrinolysis enzyme activity, there was a hypercoagulable state in patients with melanoma, and whether differences existed between those with or without metastases. Seventy-one patients were studied, 45 with localized tumors (stages Ia and Ib) and 26 with metastases (stages II-IV). Plasma level of activated factor VII, prothrombin fragment 1+2, thrombin-antithrombin complex, fibrinopeptide A, plasmin-antiplasmin complex and D-dimer were much higher in the whole group of 71 patients than in 45 controls with benign nevi. However, when melanoma patients with or without metastases were compared, there were smaller differences, with only thrombin-antithrombin complex, plasmin-antiplasmin and D-dimer significantly higher in metastatic melanoma. These results indicate that in patients carrying a tumor endowed with high procoagulant activity in vitro, there is a laboratory picture of hypercoagulability with secondary hyperfibrinolysis in vivo. However, differences between patients with localized and metastatic tumors for markers of hypercoagulability are not striking, in spite of the fact that metastatic cells support greater coagulant activity than primary cells in vitro.
\end{abstract}

Key words: melanoma, hypercoagulability, activated factor VII. Corresponding Author: Pier Mannuccio Mannucci, Via Pace 9, 20122 Milan, Italy. 
Malignant melanoma is a tumor of neuroectodermic origin endowed with peculiar effects on blood coagulation. Studying extracts of primary tumor cells obtained at biopsy or surgery, Gambacorta-Passerini et al. [1] identified a procoagulant activity with the functional characteristics of an activator of factor $X$. Further biochemical and immunological studies demonstrated that the factor $X$ activator from melanoma cells is a cysteine protease $[1,2]$, whereas benign melanocytic nevi studied as controls were devoid of such enzymatic activity [1]. It was also observed that cellular extracts from metastatic lesions were at least four times more enzymatically active than primary lesions [1]. Melanoma-derived cell lines also expressed tissue factor-like activity [3].

A few years ago, these findings prompted us to characterize in vivo the coagulation status of patients with melanoma, precisely staged for tumor localization or dissemination [4]. We found rather modest alterations of the parameters chosen for that study, such as mild increases of factors $V$ and VIII in plasma and high serum levels of fibrinogen-fibrin degradation products [4]. Such alterations were not strikingly greater in patients with metastatic melanoma than in those with localized tumors, in contrast with marked differences in procoagulant activities found in vitro [1].

Our incapacity to differentiate localized from metastatic melanoma by coagulation measurements might be due to the insensitivity of the tests chosen. The measurement of the plasma levels of coagulation zymogens, proactivators and regulatory proteins [4] is perhaps unable to reveal the subtle changes of coagulation enzyme activity induced by procoagulant moieties from melanoma cells. In the past few years, more sensitive analytical methods became available, such as those that measure directly or indirectly active enzymes in the coagulation and fibrinolytic systems [5]. This methodological progress prompted us to reinvestigate whether or not, using such highly sensitive markers, it would be possible to demonstrate more clearly hypercoagulability in patients with melanoma, and whether hypercoagulability was more marked in patients with metastatic disease.

\section{MATERIALS AND LETHODS}

Patients and controls. Seventy-one patients with melanoma, referred consecutively to the National Cancer Institute of Milan, consisted of 45 patients without metastases (18 women and 27 men, median age 51 years, range 16-78) and 26 patients (16 women and 10 men, median age 55 years, range 29-81) with metastases (stages II, III or IV). The tumor stage was established according to previously described criteria [4]. Histological diagnosis was verified in all cases after surgery. Controls consisted of 45 individuals ( 18 women and 27 men, median age 50 years, range $14-$ 79) with benign melanocytic nevi. Previous or current thromboembolic disorders, anticoagulant and hormonal therapy and surgery in the last ten days were criteria for exclusion from the 


\section{study .}

Blood collection and plasma preparation. Blood collection was performed by venipuncture using a $19 \mathrm{G}$ needle connected to an outlet into siliconized glass vacuum tubes. The first tube was discarded; the next (containing citrate, heparin and aprotinin in unknown concentrations) was used for fibrinopeptide A assay and was supplied by the kit manufacturer (see below); for the remaining coagulation assays blood was collected into tubes containing $1 / 10$ volume of $3.8 \%$ trisodium citrate. After filling, tubes were mixed by inverting them several times and placed in melting ice, except that used for measuring activated factor VII. Blood was centrifuged within $60 \mathrm{~min}$ of collection at $4^{\circ} \mathrm{C}$ for 20 min at $2000 \times \mathrm{g}$, aliquots of plasma were snap-frozen and stored at $-80^{\circ} \mathrm{C}$ until tested within two months.

Methods. Fibrinopentide $A$, an index of fibrin formation from fibrinogen, was measured by ELISA in plasma extracted twice with bentonite to remove fibrinogen (Diagnostica Stago, Asnieres, France) Prothrombin fragment $1+2$ (an index of activated factor $x$ activity on prothrombin), thrombin-antithrombin complex (an index of thrombin formation), plasmin-antiplasmin complex (an index of plasmin formation) and D-dimer (an index of lysis of cross-linked fibrin) were measured by ELISAs (Enzygnost F1+2, TAT and PAP, Behringwerke, Marburg, Germany; and Dimertest, Agen, Biomedical, Brisbane, Australia). Activated factor VII (factor VIIa, the enzymatic form of factor VII), was measured by a onestage, prothrombin time-based assay using a truncated soluble form of recombinant tissue factor (kindly supplied by Dr. Y. Nemerson, Mount Sinai Hospital Medical School, New York, NY), that upon relipidation reacts with factor VIIa but not with factor VII zymogen [6].

statistical analysis. Since the values of coagulation markers were not normally distributed, logarithmic transformation was carried oul and normalization was obtained. Descriptive statistics include geometric means and $95 \%$ confidence limits. Linear correlation coefficients ( $r$ values) were also calculated. $\mathrm{P}$ values lower than 0.05 were regarded as statistically significant.

\section{RESULTS}

We first compared all the 71 melanoma patients, whether or not they had metastatic disease, with the controls with nevi. There were differences between controls and patients, who had a laboratory picture reflecting heightened coagulation and fibrinolysis enzyme activity (Table 1). Factor VIIa was significantly increased; there were also signs of enhanced thrombin generation (expressed by high plasma levels of prothrombin fragment $1+2$ and thrombin-antithrombin complex); of fibrin formation, expressed by high levels of fibrinopeptide $A$ and of plasmin activity, expressed by high levels of D-dimer and plasmin-antiplasmin complex (Table 1). However, when melanoma patients with and without metastases were compared, there was little difference in the plasma levels of coagulation activation markers, with only thrombin-antithrombin complex ( $P=0.01$ ) (Fig. 1), D-dimer $(P<0.001) \quad(\mathbf{F i q . 2})$ and plasmin-antiplasmin complex 
$(\mathrm{P}=0.001)$ (Fig. 3) higher in metastatic melanoma. Table 2 shows the correlation coefficients of the activation markers.

TABLE 1

\begin{tabular}{|c|c|c|c|c|c|c|}
\hline \multirow[t]{4}{*}{ Measurements } & \multirow{4}{*}{$\begin{array}{l}\text { Melanocytic } \\
\text { nevi } \\
\text { (1) }\end{array}$} & \multirow{4}{*}{$\begin{array}{l}\text { All } \\
\text { melanomas }\end{array}$} & \multirow{4}{*}{$\begin{array}{l}\text { Localized } \\
\text { melanomas } \\
\text { stage I } \\
\text { (3) }\end{array}$} & \multirow{4}{*}{$\begin{array}{l}\text { Metastat ic } \\
\text { melanomas } \\
\text { stage II-IV } \\
\text { (4) }\end{array}$} & \multicolumn{2}{|c|}{ p values } \\
\hline & & & & & $1 \underline{\mathrm{vg}} 2$ & $3 \underline{v g} 4$ \\
\hline & & & & & & \\
\hline & & & & & & \\
\hline Act ivated factor VTI & 2.90 & 3.63 & 3.52 & 3.84 & & \\
\hline (FVIIa) ng/ml & $(2.61-3.24)$ & $(3.36-3.93)$ & $(3.16-3.93)$ & $(3.43-4.29)$ & 0.0008 & N.S. \\
\hline Prothrombin & 0.92 & 1.26 & 1.11 & 1.24 & & \\
\hline $\begin{array}{l}\text { fragment } 1+2(\mathrm{~F} 1+2), \\
\text { nmol/L }\end{array}$ & $(0.83-1.01)$ & $(1.06-1.26)$ & $(0.99-1.24)$ & $(1.08+1.42)$ & 0.0008 & $\underline{\text { N.S. }}$ \\
\hline Thrombin/antithrombin & 2.45 & 3.03 & 2.65 & 3.84 & & \\
\hline complex (TAT), ng/ml & $(2.22-2.72)$ & $(2.62-3.51)$ & $(2.23-3.16)$ & $(3.01-4.89)$ & 0.034 & 0.01 \\
\hline Fibrinopeptide A (FPA) & 0.90 & 1.20 & 1.19 & 1.21 & & \\
\hline $\mathrm{nmol} / \mathrm{L}$ & $(0.81-1.00)$ & $(1.08-1.32)$ & $(1.04-1.35)$ & $(1.01-1.45)$ & 0.0003 & N.S. \\
\hline D-Dimer $(D-D)$. & 41 & 71 & 47 & 142 & & \\
\hline $\mathbf{n g} / \mathbf{m} \mathbf{l}$ & $(35-47)$ & $(55-91)$ & $(36-62)$ & $(94-215)$ & 0.0017 & 0.0001 \\
\hline Plasmin-ant iplasmin & 331 & 393 & 338 & 511 & & \\
\hline complex (PAP), ng/m 1 & $(301-365)$ & $(357-433)$ & $(312-366)$ & $(422-615)$ & 0.018 & 0.001 \\
\hline
\end{tabular}

Values are given as geometric means and, between parenthesis, 95 per cent confidence intervals

TABLE 2

Correlation coefficients ( $r$ values) between markers of coagulation and fibrinolysis enzyme activity in all patients with melanoma.

\begin{tabular}{|c|c|c|c|c|c|}
\hline & $\mathrm{Fl}+2$ & FPA & TAT & D-D & PAP \\
\hline rvila & $0.35^{*}$ & 0.03 & 0.21 & $0.21^{+}$ & 0.15 \\
\hline $\mathrm{F} 1+2$ & & 0.11 & $0.54^{\star}$ & $0.51^{*}$ & 0.25 \\
\hline FPA & & & $0.36^{*}$ & $0.30^{\star}$ & $0.44^{\star}$ \\
\hline TAT & & & & $0.71^{\star}$ & $0.55^{*}$ \\
\hline$D-D$ & & & & & $0.72^{*}$ \\
\hline
\end{tabular}

$+P<0.05$

- $P<0.01$ 


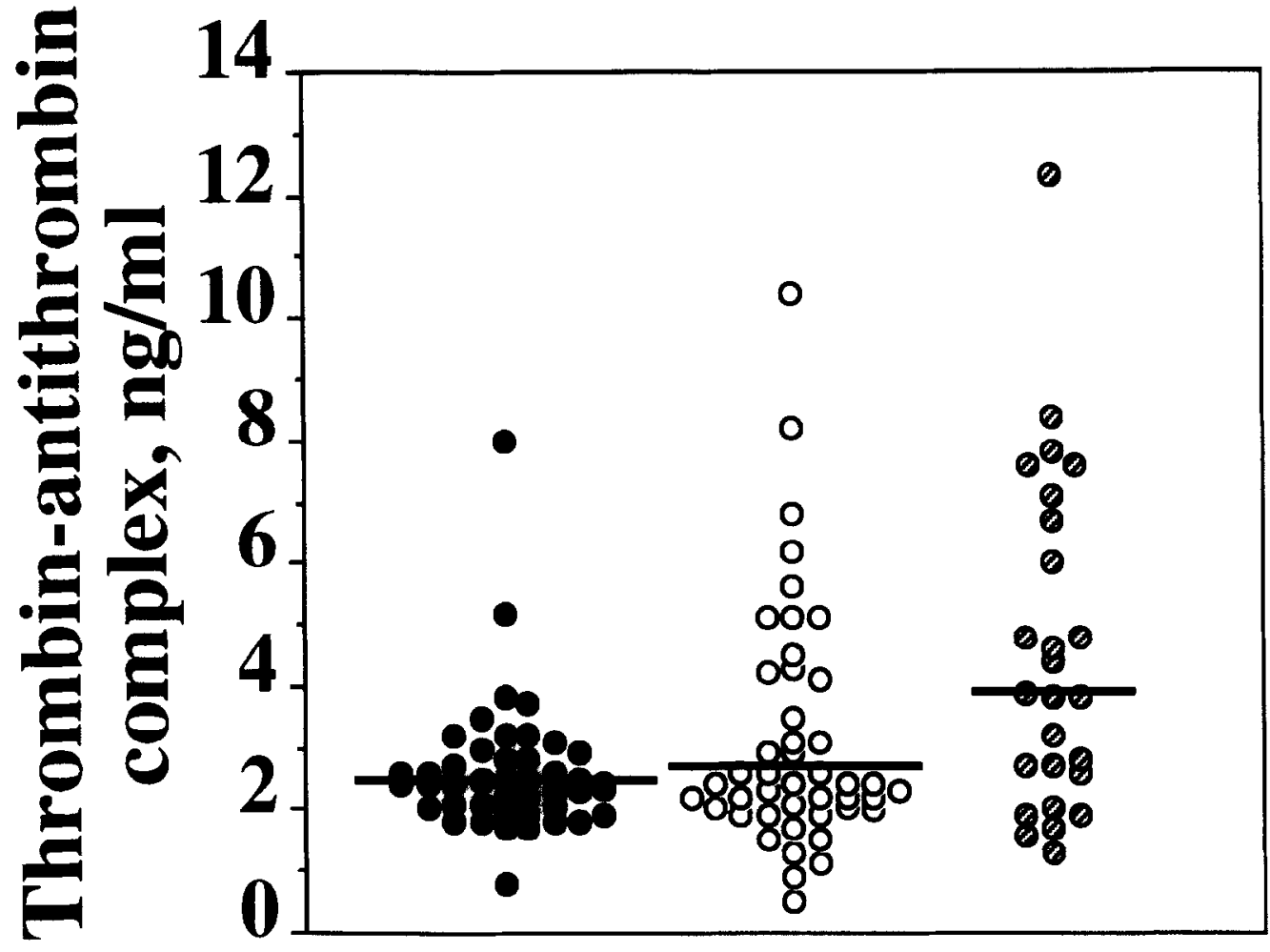

Figure 1. Plasma concentrations of thrombin-antithrombin complex in patients with melanocytic nevi (solid circles), localized melanoma (open circles) and metastatic melanoma (striped circles). The horizontal lines denote the geometric mean value of each parameter in each group.

\section{DISCUSSION}

The sensitive direct or indirect markers of coagulation and fibrinolysis enzyme activity employed in this study document the existence of a laboratory state of hypercoagulability and hyperfibrinolysis in several melanoma patients. However, patients with and without metastases could not be clearly distinguished. According to the in vitro characterization of the procoagulant activities of primary and metastatic melanoma cells [1], the latters should activate coagulation to a greater degree. Only Ddimer, an index of intravascular or extravascular fibrin formation and lysis, and, to a lesser extent, thrombinantithrombin and plasmin-antiplasmin complexes, indexes of heightened thrombin formation and fibrinolysis, were significantly higher in patients with metastases than in those without. 
Hypercoagulability appeared to be mainly triggered by the activation of the tissue factor pathway, as shown by high levels of factor VIIa, the key enzyme generated in the pathway by tissue factor-factor VII-factor VIIa interactions [7]. The elevation of factor VIIa, the principal physiological activator of factor $\mathrm{X}$, would mechanistically explain why factor xa activity is high,

resulting in turn in a greater cleavage of prothrombin and increased formation of the fragment $1+2$. Heightened prothrombin activation would then lead to greater thrombin generation (reflected by high levels of thrombin-antithrombin complex). fibrin formation (high fibrinopeptide A) and secondary fibrinolysis (high D-dimer and plasmin-antiplasmin complex). The values of the markers of coagulation activation were in general correlated with those of hyperfibrinolysis, supporting the views that they are associated phenomena.

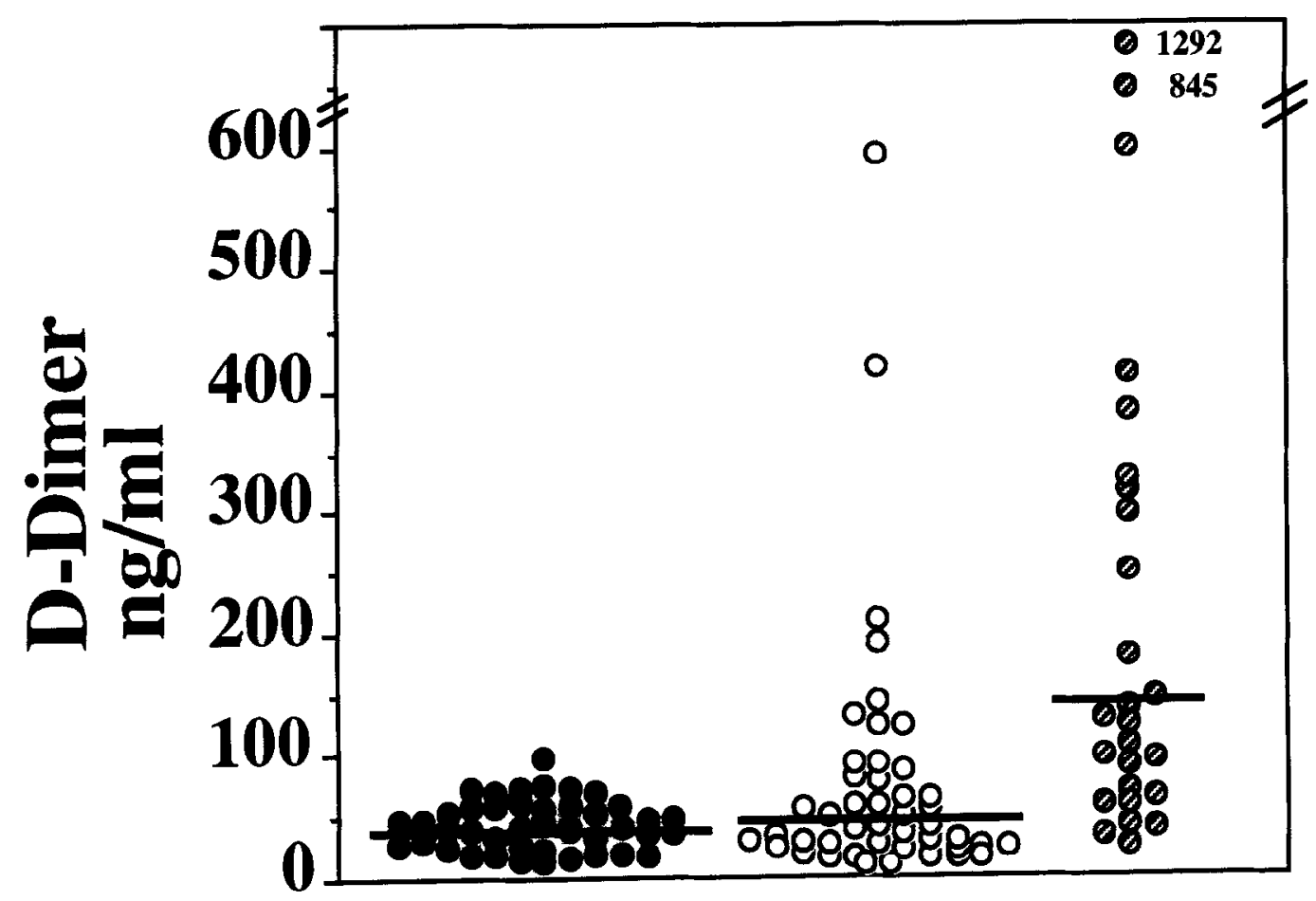

Figure 2. Plasma concentrations of D-dimer. See Fig. 1 for symbols.

The mechanisms underlying the activation of factor VII are still speculative. Activation may be mediated by the exposure on melanoma cells of tissue factor, a feature common to many tumor cells [8]. Factor VIIa may also be generated on tissue factor exposed on monocytes or other cells activated by the malignant cells [9, 10]. Since no increase was found in markers of 
coagulation enzyme activity as tumor burden increased, it is hard to imagine that factor VII activation is engendered by the tumor, which may suggest that perhaps it is from monocytes or other tumor activated cells. Finally, elevations of markers may also be triggered by the peculiar factor $\mathrm{X}$ activator expressed by melanoma cells $[\mathbf{1}, \mathbf{2}]$.

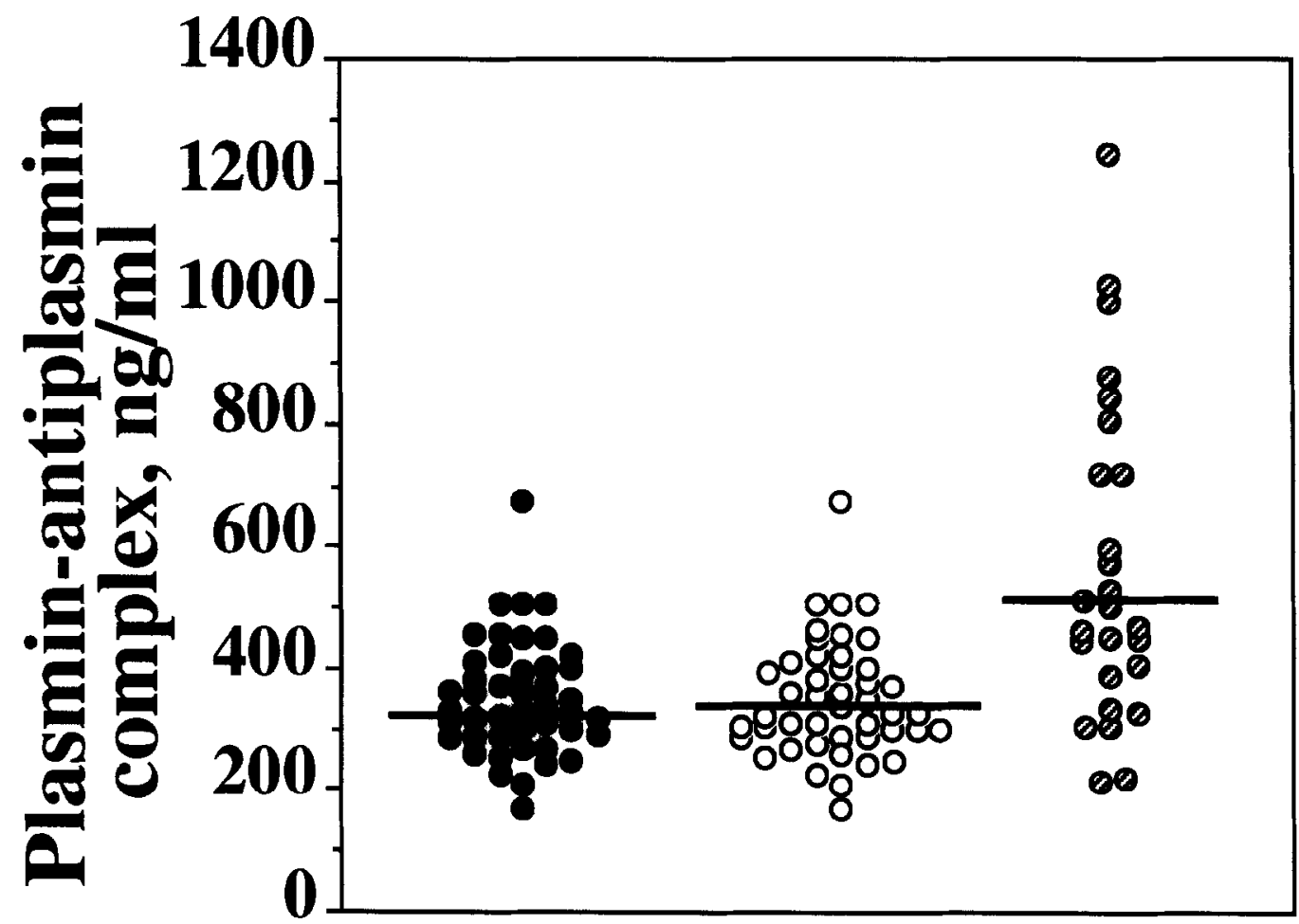

Figure 3. Plasma concentration of plasmin-antiplasmin complex. See Fig. 1 for symbols.

In conclusion, this study has characterized with sensitive markers of enzyme activity the coagulation and fibrinolysis status of patients with melanoma. A hypercoagulable state exists in the majority of these patients, even in the early stages of the disease without metastases, leading to fibrin formation and secondary fibrinolysis. The pathophysiological significance of the alterations remains to be established. The hypercoagulable state may facilitate the tendency of these patients to develop thromboembolic complications. Perhaps increased fibrin formation may also provide a network that would facilitate dissemination of melanoma cells from the primary tumor and enhance metastases formation, but this remains to be established with clinical trials of anticoagulants agents. 
Acknowledgements. This study was supported in part with a grant from Assocazione per la Ricerca sul Cancro.

\section{REFERENCES}

1. GAMBACORTA-PASSERINI, C., FOSSATI, G., SEMERARO, N., DONATI, M.B. and GORDON, S.G. Cancer procoagulant and haemostatic abnormalities in melanoma. Lancet $1,920,1986$.

2. FALANGA, A. and GORDON, S.G. Solution and characterization of cancer procoagulant: a cysteine proteinase from malignant tissue. Biochemistry 24, 5558-5567, 1985.

3. CAJOT, J.F., KRUITHOF, E.K.O., SCHEUNING, W.D., SORDAT, B., and BACHMANN, F. Plasminogen activators, plasminogen activators inhibitors and procoagulant analyzed in 20 human tumor cell lines. Int $J$ Cancer 38, 719-725, 1986.

4. MANNUCCI, P.M., VAGLINI, M., MANIEZZO, M., MAGNI, E., MARI, D. and CASCINELLI, N. Hemostatic alterations are unrelated to the stage of tumor in untreated malignant melanoma and breast carcinoma. Eur J Cancer Clin Oncol 21, $681-685,1985$.

5. MANNUCCI, P.M.. Mechanisms, markers and management of coagulation activation. Br Med Bull 50, 851-870, 1994.

6. WILDGOOSE, P., NEMERSON, Y., HANSEN, L.L., NIELSEN, F.B., GLAZER, $\mathbf{S}$. and HEDNER, $\boldsymbol{d}$. Measurement of basal levels of factor VIIa in hemophilia A and B patients. Blood 80, 25-33, 1992 .

7. EDGINGTON, T.S., MACKMAN, N., BRAND, K. and RUF, w. The structural expression and function of tissue factor. Thromb Haemostas 60, 67-71, 1991.

8. FRANCIS, J.L. Hemostasis and cancer. Med Lab Sci 46, 331$341,1989$.

9. EDWARDS, R.L., RICKLES, F.R. and CRONLUND, M. Abnormalities of blood coagulation in patients with cancer: mononuclear cell tissue factor generation. J Lab Clin Med 98, 917-926, 1981 .

10. MORGAN, D., EDWARDS, R.L. and RICKLES, F.R. . Monocyte procoagulant activity as a peripheral marker of clotting activation in cancer patients. Haemostasis 18: 55-62, 1988. 